\title{
Scientific individualism shrinks
}

\author{
Michael Gurevitz* \\ The George S. Wise Faculty of Life Sciences, Tel Aviv University, Tel Aviv, Israel
}

Darwin's contribution to better understanding of evolution is an example of revolutionary science based on observations and interpretations by an individual. Nowadays, however, substantial advances in certain fields of experimental sciences often require integrated efforts of large research groups sometimes conglomerates with access to almost unlimited resources. This difference raises an evident question of whether scientific output by individuals is presently at descent. Certainly, in today's 'battlefield' of competitive science the larger, more equipped your 'army', the higher the probability for outstanding output. Indeed, major scientific breakthroughs during the modern era (e.g., 'Big bang theory'; identification of new subatomic elements; 'Human genome project'; discovery of the AIDS virus) would not have been achieved without cumulative efforts and enormous financial investments. Ironically, this new reality, leading inexplicably to depreciation of scientific individualism, follows a flourishing era, approximately half a millennium, of substantial scientific discoveries by creative individuals. Can this shift in scientific capabilities be attributed to only fund-raising difficulties and larger working networks? As much as it is enticing to denounce these factors, the forces enabling or limiting science advancement are more complex. One needs to consider the history of science development, which evidently was accompanied by development of logical capabilities and rational thinking. Although individuals with exceptional minds had always been around (e.g., Greek philosophers, curious priests, crown-supported 'scientists' or 'physicians', artists), we should remember that prior to the 'Scientific Renaissance', at the third phase of the Middle-Ages, most uncertainties in our life and the surrounding world were still apprehended as marvels frequently attributed to God's creativity. What was it then just a few centuries ago that incited the public awareness and desire to better understand the wonders of Nature in a reality where the majority of the people were convicted to conceptions describing the origin of mankind as a'miraculous creation' rather than evolution? The conversion of public mind at these years toward scientific rationalization of the unexplained was therefore quite amazing. Such revolutionary transformation likely rested on the increased trust in Science not just as a prime tool for better understanding of Nature, but also as a useful means for improving daily life, and therefore it must have required new socioeconomical and political conditions. Most important was probably the lift of tyrannical control over peoples' mind (e.g., monarchism, church),

Copyright: (C)2020 Gurevitz M. This is an open-access article distributed under the terms of the Creative Commons Attribution License, which permits unrestricted use, distribution, and reproduction in any medium, provided the original author and source are credited. especially effective at developing urban societies and paving the way to fearless thinking, creativity and communication. Public education and freedom of occupation expedited these alterations supporting equal opportunities and broader horizons. At that stage, apprehension of the benefits of new inventions was critical for establishment of conceptually and physically permissive atmosphere, while abandoning religious predispositions as well as superstitions and deep phobia. The eyes of the public opened with strong ambition to solve daily concerns for better life. With the development of appropriate means, aspirations climbed as high as 'looking to the stars' in an attempt to understand the creation of the universe and what is beyond. Interestingly, it has taken thousands of years before these prerequisites were met, but as they did they swiftly perpetuated particularly when realizing that careful observations and experimentations using suitable tools might provide rational answers to many challenging uncertainties. This 'Scientific Renaissance' climaxing at the 'Industrial revolution' was typified by great discoveries of individuals and persisted till approximately the beginning of the 20th century, when the 'bloom' of modern science was ensued by the claim 'not much has been left to discover', which held sway for decades. Although it may presently sound ridiculous, this claim is not totally out of proportion considering the decrease in breaking scientific output by individuals and in light of fundamental discoveries achieved by cumulative efforts of 'scientific tycoons' (academic and industrial conglomerates). The emerging question is then how do we foresee future science in a world 'rushing' toward globalization in every aspect of life. Would science be left in the hands of 'Tycoons' while individualism shrinks, or may we trust that the need for distinguished individual minds (e.g., L. da-Vinchi, A. Einstein, S. Hawking, P. Higgs and F. Englert) would always persist? With more than a grain of optimism (how could we live otherwise?) and as long as the cumulative human lore is unable to perceive or explain basic riddles of our world (e.g., the origin of energy/matter in the universe prior to the Big Bang; or, how brain organization and functionality constitute the human spirit or soul), we might still rely on exceptional minds capable of 'out of box' thinking for rationalizing the unexplained. Thus, scientific individualism may presently be at descent, but our inherent optimism (a luckily built-in default) suggests it would never dissipate, 'so help us God'.
${ }^{\star}$ Correspondence to: Michael Gurevitz, The George S. Wise Faculty of Life Sciences, Tel Aviv University, Tel Aviv, Israel, Tel: 03-6409844/09-7717160; Fax: 03-6406100; E-mail: mickeyg@tauex.tau.ac.il

Received: April 16, 2020; Accepted: May 05, 2020; Published: May 08, 2020 